Revue des patrimoines

$20 \mid 2013$

Les patrimoines de la traite négrière et de l'esclavage

\title{
Les patrimoines de la traite négrière et de l'esclavage
}

Editorial

\section{Vincent Berjot}

\section{(2) OpenEdition}

\section{Journals}

Édition électronique

URL : http://journals.openedition.org/insitu/10296

DOI : 10.4000/insitu. 10296

ISSN : 1630-7305

\section{Éditeur}

Ministère de la Culture

\section{Référence électronique}

Vincent Berjot, «Les patrimoines de la traite négrière et de l'esclavage », In Situ [En ligne], 20 | 2013,

mis en ligne le 12 juin 2013, consulté le 22 septembre 2020. URL : http://journals.openedition.org/ insitu/10296 ; DOI : https://doi.org/10.4000/insitu.10296

Ce document a été généré automatiquement le 22 septembre 2020.

\section{(ब) $\odot \Theta$}

In Situ Revues des patrimoines est mis à disposition selon les termes de la licence Creative Commons Attribution - Pas d'Utilisation Commerciale - Pas de Modification 4.0 International. 


\section{Les patrimoines de la traite négrière et de l'esclavage}

Editorial

\section{Vincent Berjot}

1 Ce numéro d'In Situ, revue des patrimoines, présente les communications faites à l'occasion du colloque organisé par la direction générale des patrimoines les 27, 28 et 29 avril 2011 à La Rochelle, en partenariat avec l'Université de La Rochelle, le Conseil général de Charente-Maritime, la Ville de La Rochelle et le Centre des monuments nationaux. Il s'agissait d'évoquer la mémoire, les traces, les vestiges qui portent témoignage d'une histoire longtemps occultée dans laquelle toutes les valeurs, tous les principes de morale et de justice aujourd'hui portés par la République, furent bafoués. (Voir le programme en annexe). 


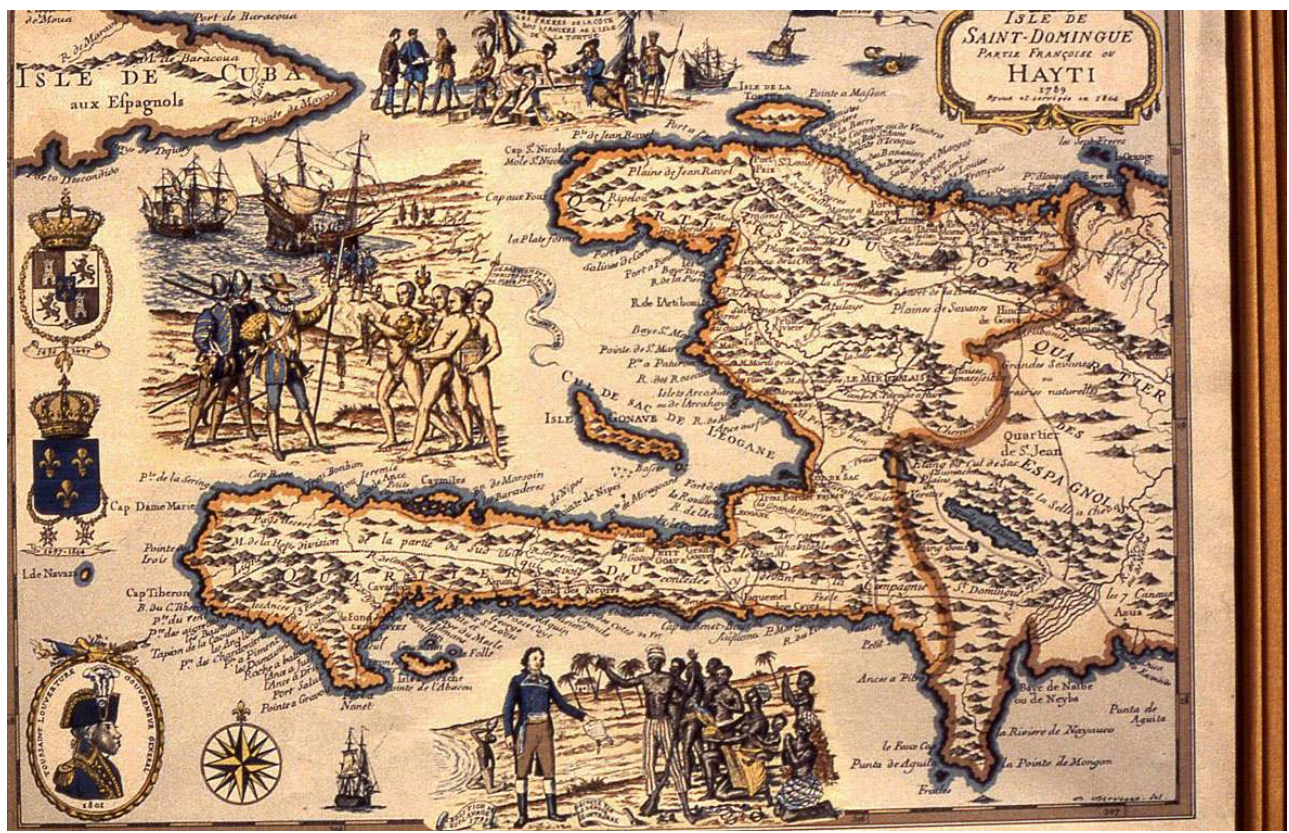

Carte de la partie française de Saint-Domingue ou Haïti, 1789-1804. En cartouches, de gauche à droite : armes d'Espagne et de France, arrivée de Christophe Colomb; les Frères de la Côte, flibustiers et boucaniers ; libération des esclaves par le commissaire civil Sonthonax ; médaillon de Toussaint Louverture.

(C) J. de Cauna, 1984.

2 En 1848, Victor Schœlcher invente à propos de l'esclavage la notion d'« attentat contre la dignité humaine ", concept qui marque une importante avancée dans la prise en compte du droit des personnes collectivement victimes d'injustice. Son influence en droit international est sensible jusqu'à notre époque. C'est ainsi que le passé éclaire l'actualité, que la pratique de la Traite s'inscrit dans l'histoire universelle des hommes et des femmes qui, à toutes les époques et en différents lieux, ont été ou sont encore aujourd'hui asservis, privés de leur libre arbitre et de leur dignité d'êtres humains parce que différents.

3 Les nombreuses recherches menées depuis plusieurs années par les historiens, ont profondément renouvelé la connaissance de cette histoire complexe, lui redonnant sa juste place dans notre histoire nationale. Leurs travaux ont nourri de nombreux débats, parfois vifs, sans doute nécessaires, qui eurent le mérite de révéler à l'ensemble de nos concitoyens la brûlante actualité du sujet. Ils constituent un solide socle scientifique sur la base duquel il est désormais possible de mener la réflexion sur ce qui fait patrimoine dans ce domaine et de dessiner les grandes lignes d'une politique patrimoniale éclairée.

4 C'est l'objectif ambitieux que s'est fixé la direction générale des patrimoines du ministère de la Culture qui a réuni pour ce faire un comité scientifique placé sous la présidence de Françoise Vergès, comité constitué d'historiens et de professionnels du patrimoine, qui s'est totalement investi dans la préparation de cette manifestation scientifique.

5 À la suite du remarquable travail de recensement des sources coordonné par les Archives de France, dont les principes et les résultats sont évoqués dans plusieurs des articles ici publiés, et pour répondre pleinement aux attentes d'une part grandissante 
de nos concitoyens, le temps est venu d'envisager le patrimoine lié à l'histoire de la Traite transatlantique dans sa globalité et dans toute la complexité d'un phénomène historique s'étendant sur près de quatre siècles, concernant trois continents, et touchant à l'ensemble des champs patrimoniaux, archéologie, archives, livre, patrimoine linguistique, patrimoine immatériel, architectures et objets.

6 Il faut le reconnaître, ce patrimoine a été longtemps ignoré, au point que certains parlent encore d'une histoire sans patrimoine. Récemment, quelques pays dont la Grande-Bretagne, des villes françaises telles que Nantes, Bordeaux et La Rochelle se sont réapproprié cette part importante de leur passé.

7 Loin de détourner nos regards, nous devons interroger les objets et les pratiques qui témoignent encore de cette douloureuse histoire. Notre devoir est de les faire parler, de les rendre compréhensibles et accessibles à tous, de les transmettre aux générations futures.

Figure 2

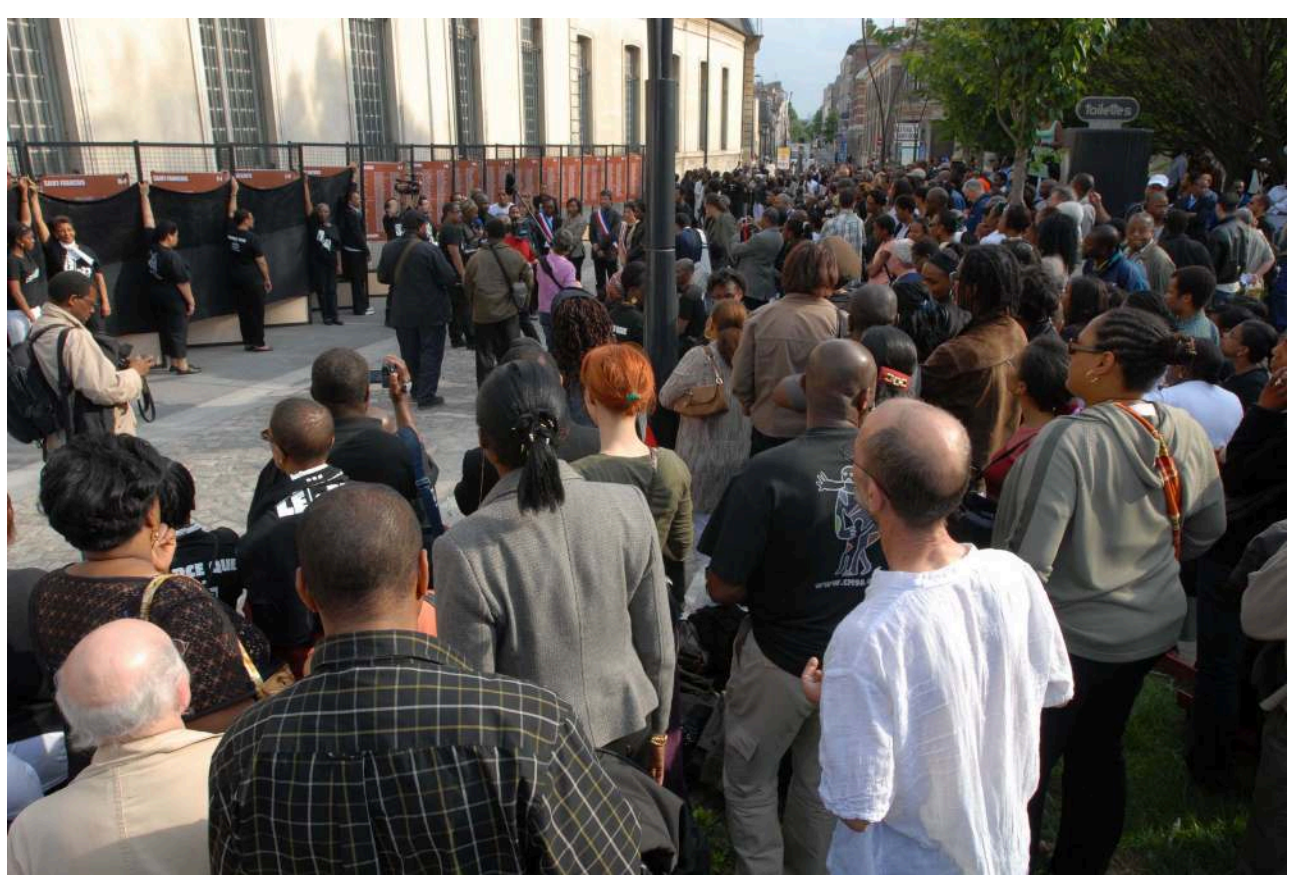

Inauguration du Mémorial « les Noms de l'abolition » le 23 mai 2008.

(c) E. Gordien.

8 Les spécialistes dont les textes sont ici rassemblés jouent à cet égard le rôle d'éclaireurs. Tous œuvrent à la connaissance, à la préservation et à la mise en valeur du patrimoine de la Traite. Historiens, historiens de l'art, archivistes, archéologues, linguistes, ethnologues, universitaires et conservateurs d'Europe, d'Afrique ou d'Amérique, ils ont donné à cette manifestation scientifique une envergure réellement internationale et pleinement transdisciplinaire. Le sujet l'exigeait : de ce point de vue, ce numéro d'In Situ constitue une première. Tous ont beaucoup à nous apprendre et cette publication a pour principal objectif de mieux faire connaître leurs travaux, de mettre en lumière leurs actions, pour sensibiliser les professionnels, le monde associatif et tous les citoyens à ce patrimoine vivant. 


\section{AUTEUR}

\section{VINCENT BERJOT}

Directeur général des patrimoines, ministère de la Culture et de la Communication 